\title{
Factors Influencing Non-Disclosure of Child Sexual Abuse Amongst Bapedi Tribe in Polokwane, Limpopo Province, South Africa
}

\author{
Rapholo Selelo Frank ${ }^{1}$ \\ ${ }^{1}$ Department of Social Work, University of Limpopo, Sovenga, South Africa \\ Correspondence: Rapholo Selelo Frank, Department of Social Work, University of Limpopo, Private Bag X1106, \\ Sovenga 0727, South Africa. E-mail: Frank.Rapholo@ul.ac.za
}

Received: September 6, 2019 Accepted: October 1, 2019 Online Published: October 15, 2019

doi:10.5539/gjhs.v11n12p175 URL: https://doi.org/10.5539/gjhs.v11n12p175

\begin{abstract}
Child sexual abuse is a global public health issue calling the attention of practitioners, scholars and policy makers to address it. This study argues that children are being sexually abused both by family and non-family members, and such incidents are not always reported and/or disclosed due to various influential factors. This study was aimed at exploring and describing possible influential factors for the non-disclosure of child sexual abuse amongst Bapedi tribe. A qualitative approach with a descriptive phenomenological design was followed. Fifteen caregivers of children were purposively selected in order to pursue the aim of this study. Data was collected through semi-structured interviews and analysed thematically through the help of Nvivo Software. The findings indicate that due to factors such as fear of the perpetrator, the practice of the spirit of ubuntu, socio-economic status of the family and relationship with the perpetrator, protecting the dignity of the family, fear of victimisation, fear of witchcraft, and cultural beliefs, child sexual abuse in the Bapedi tribe is an issue to be dealt with by families affected and if need be, traditional courts intervene in case the families disagree. It can therefore be concluded that there is a lack of information on the nastiness of child sexual offences against children amongst Bapedi tribe. Therefore, the Bapedi tribe must be empowered to disclose and/or report child sexual abuse and the implications of not doing so.
\end{abstract}

Keywords: bapedi tribe, child, child sexual abuse, non-disclosure

\section{Introduction and Background}

Sexual abuse of children is a serious social and health issue that affects children and their caregivers globally. South Africa has been branded as the 'rape capital of the world (Calitz, 2011; Sumampouw, Otgaar, La Rooy \& de Ruiter, 2019). There is a high volume of reported cases of child sexual abuse allegations in South Africa. This is confirmed by the South African Police Service (SAPS) crime stat 2016/17 and 2017/18. In the year 2016/17, 49 600 sexual offences against children in South Africa were registered at SAPS and in year 2017/18, 50108 sexual offences cases against children were also reported. Thus, there was a slight increase of 0.448 cases which were reported at SAPS between the years 2016/17 and 2017/18. According to Rapholo and Makhubele (2019), the statistics on sexual offences against children in South Africa are unsettling and lead to the re-victimisation of children. Unfortunately, child sexual abuse has psychological and emotional implications on the well-being of child victims. This supports Borg et al. (2014), Daray et al. (2016) and Widom and Massey (2015) who postulate that child sexual abuse has life-long devastating impact on the well-being of the child victim. Widom and Massey further state that this social ill has serious physical, psychological, social and health consequences.

Care and protection of children in South Africa is regulated by the Children's Act 38 of 2005 as amended and it is believed that children are supposed to be safe, valued and encouraged to grow and develop (Rapholo, 2014). Inspite of these initiatives, child sexual abuse is still alarming. In the same breath, Sumampouw, Otgaar, La Rooy and de Ruiter (2019) denote that child sexual abuse violates pieces of legislations such as the UN Convention of the Rights of the child which is aimed at protecting children from any kind of sexual abuse. The dilemma with child sexual abuse is the disclosure. Most children are being sexually abused both by family and non-family members and such incidents are not always disclosed and/or reported (Rapholo, 2014). Pragmatically, the researcher has noted in areas around Polokwane that children do not easily disclose sexual abuse, more especially if it is intra-familial abuse. This confirms Rapholo and Makhubele's (2019) study on forensic interviewing that children are prepared within their families to not share to the public any upsetting intimate details of family life. 
Practices of this nature influence children not to talk about sexual abuse, more especially to people outside their families. This study therefore was aimed at exploring and describing influential factors for the non-disclosure of child sexual abuse amongst Bapedi tribes around Polokwane in the Limpopo Province of South Africa.

\subsection{Research Problem}

The disclosure of child sexual abuse is a process. Children are reluctant to disclose information about abuse (Chabeletsane, 2015; Cronch et al., 2006; Rapholo, 2018) due to various factors. In the same wavelength, Spies (2006) avers that children are silenced by threats, blame and bribery to not disclose sexual abuse. Child victims of sexual abuse according to the study conducted by Rapholo (2014) do not always willingly disclose sexual abuse to anyone until they gain trust of that person such as their caregivers. According to De Voe and Faller (2002) and Malloy and Lyon (2013), many children find it difficult to talk about their sexual abuse experiences due to their caregiver's reactions. Spies (2006) and Ntlatleng (2011) denote that caregivers assume a very crucial role on the development of child. Thus, they should support children to speak out against the person who sexually abused them. To support these sentiment, Getz (2013) states that sexually abused child fares better in the disclosing process when a caregiver is involved. This study argues that children are being sexually abused both by family members and non-family members, and such incidents are not always reported and/or disclosed due to various influential factors. The researcher has practically on working with children who are alleged to be sexually abused noticed that the disclosure often takes time. There are lot of variables such as relationship with the perpetrator, parental support, culture, age, gender, duration of abuse and post-traumatic stress and modesty that affect the disclosure patterns amongst children who are alleged to be sexually abused (Dawes \& Higson-Smith, 2005; Lamb et al.,2008).

Family and societal rules, norms and standards also play a role in children's reluctance not to disclose sexual abuse. Rapholo (2014) states that caregivers teach their children to adhere to family and societal rules, norms and standards, thus forcing them (unintentionally) to keep sexual abuse secret. This result in children becoming targets for sexual abuse within their families and communities. Sometimes they become vulnerable to the significant others, such as teachers, and other men in authorities they trust that may force them into undesired sexual intercourse (Dawes \& Higson-Smith, 2005; Ferrara, 2002; Meadow et al., 2007).

The notion of child sexual abuse sometimes depends on what an ethnic group validates as sexual abuse (Chabeletsane, 2015; Ngubane, 2010; Rapholo, 2018). Perspectives and meanings vary from one ethnic group to another. There are different sets of guidelines according to tribes which individuals inherit as members of a particular society which also inform them how to experience and interpret their world (Dawes \& Higson-Smith, 2005). For example, what Bapedi tribe validates as child sexual abuse can be the reason why they do not disclose. This study argues that the disclosure of child sexual abuse vary from one tribe to another. There are various influential factors according to the different tribes, particularly in the Limpopo province of South Africa that contribute to the non-disclosure of child sexual abuse. The researcher has not come across any study which specifically zoomed at such factors in the context of Bapedi tribe. Given that there high rate of sexual abuse cases in South Africa as supported by the statistics in this paper, the researcher developed an interest to investigate factors influencing the non-disclosure of child sexual abuse amongst Bapedi tribes around Polokwane in the Limpopo province of the country.

\subsection{Aim of the Study}

This study was aimed to explore and describe factors influencing non-disclosure of child sexual abuse amongst Bapedi tribe.

\subsection{Theoretical Framework}

The ecosystems theory is used as a framework in this study to zoom into systems which are at play amongst Bapedi tribe to contribute to the non-disclosure of child sexual abuse. The ecosystems theory looks at the interrelatedness of people and their environment (Weyers \& Geyers, 2011; Mbezi, 2019). The interest of this theory is on understanding an individual in context (Neal \& Neal, 2013). It explains the nature of social problems as lack of adaptive fit between the two. This theory in this study view the non-disclosure of child sexual abuse as influenced by the context with which children from the Bapedi tribe find themselves in. This theory was more relevant and appropriate in this study to understand the nexus between the Bapedi tribe and systems in which they interact with and to as well uncover how the relationship between the two influence the non-disclosure of child sexual abuse. The practice of Ubuntu amongst Bapedi tribe in this study was found to be contributing to the non-disclosure of child sexual abuse due to the fear of exposing perpetrators to a punishment by the legal authorities. The protection of the dignity and status of the family, socio-economic status of the family, fear of victimisation, cultural beliefs 
and witchcraft practices amongst Bapedi tribe were also found to have an influence on the non-disclosure of child sexual abuse. Therefore, the ecosystems theory assisted the researcher to contextually understand the non-disclosure of child sexual abuse amongst the Bapedi tribe.

\section{Research Methodology}

A qualitative approach with a descriptive phenomenological design was followed in this study. Botma et al. (2010) states that qualitative researchers are concerned with understanding rather than explanation, with naturalistic observation rather than controlled measurement (Fouché \& Schurink, 2011). The phenomenology design was used to describe factors influencing the non-disclosure of child sexual abuse amongst Bapedi tribe in Polokwane (Botma et al., 2010; Fouché \& Schurink, 2011). At the root of phenomenology is the intent to understand the phenomena under study on their own terms and to provide a description of human experience as it is experienced by the individual (Fouché \& Schurink, 2011). Fifteen caregivers of children in the areas around Polokwane were selected through purposive sampling technique. The participants were selected on the basis of their significance to the proposed study until data saturation was reached. Data saturation, as Strydom and Delport (2011) describe it, is the collection of data to the point where a sense of closure is attained because new data yields redundant information. Semi-structured interviews guided by an interview schedule with open ended questions were used to collect data which was analysed thematically through the help of Nvivo software. Audiotape recordings were made during the interviews with the consent of the caregivers. The main task of audiotape recording device according to Monette et al. (2008), is to record the responses of the participants. Greeff (2011) and Rubin and Babbie (2005) avow that a tape recorder is a powerful tool because it allows the interviewer to pay full attention during the interviews and be focused on respondents. The audiotape recordings were translated from Sepedi to English. Field notes by the researcher were written in English after each interview (Greeff, 2011).

\subsection{Ethical Issues}

Ethical concerns are very crucial in research. Researchers are responsible for designing and carrying out research both knowledgeably and ethically. An ethical clearance was granted from Turfloop Research and Ethics Committee and Maraba Tribal Authority for the purpose of conducting this study. A consent form which was explained to all participants was signed to allow them to voluntarily participate in this study. Participants were assured that their names and identities will not be stated on this paper in order to safeguard their confidential matters and maintain their anonymity.

\subsection{Demographical Details of the Participants}

The following table outlines the demographic details of the participants in this study.

Table 1. Demographical details of the participants $(\mathrm{N}=15)$

\begin{tabular}{lll}
\hline Characteristics & Number & Percentage \\
\hline Gender of the caregivers & 6 & $40 \%$ \\
Male & 9 & $60 \%$ \\
Female & & \\
\hline Age categories of the caregivers & 0 & 0 \\
20 years and younger & 5 & $30 \%$ \\
$21-30$ years & 5 & $30 \%$ \\
$31-40$ years & 3 & $20 \%$ \\
$41-50$ years & 1 & $10 \%$ \\
$51-60$ years & 1 & $10 \%$ \\
60 years and older & 1 & \\
\hline
\end{tabular}

The above table indicates that the majority of the participants were females as they comprised $60 \%$ of the sample, whereas male respondents made up $40 \%$ of the sample. Even though the sample was not representative, the data supports the previous studies that indicate that most of the caregivers of children are females of every age, racial, and/or ethnic group (Dawes \& Higson-Smith, 2005). However, it cannot be concluded in this paper most caregivers of children in the Bapedi tribe are females than males. 
The table also indicates that none of the participants interviewed was below the age of 20 years. The data indicates that $90 \%$ of the participants ranged from 21 to 60 years of age $(21-30=30 \% ; 31-40=30 \% ; 41-50=20 \%$; and $51-60=10 \%$ ) whereas $10 \%$ of the participants, which was only one, ranged from the age of 60 years and older. Since the study was not representative, it is not possible to conclude that most caregivers amongst Bapedi tribe range from ages 21 to 60 years.

\section{Findings of the Study}

Findings point that due to factors such as fear of the perpetrator, the spirit of ubuntu, socio-economic status of the family and relationship with the perpetrator, fear of victimisation, protecting the dignity of the family, fear of witchcraft, and cultural beliefs, child sexual abuse in the Bapedi tribe is an issue to be dealt with by families affected and if need be traditional courts intervene in case the families disagree.

\subsection{Fear of the Perpetrator}

Several studies at the international level coming down to South Africa reveal fear of the perpetrator as contributing to the non-disclosure of sexual abuse (Shackel, 2009; Spies, 2012; Esposito, 2012; Chabeletsane, 2015; Rapholo, 2018). It was found in this study that most sexual offences committed against children amongst Bapedi tribe are intra-familial, however, such matters are usually resolved by the affected families. Rapholo (2018) postulates that it is very difficult for children who have been sexually abused by their family members and relatives to disclose sexual abuse. Children who come from families which are characterised by violence, usually do not disclose abuse due to the fear of causing further violence within the family. Findings revealed that due to the fear of the perpetrator it is not easy for both children and their caregivers to disclose sexual abuse. Some participants indicated that perpetrators are mostly fathers of their children who pose threatening statements against children during the abuse scene such as "If you tell anyone, I will kill you or your mother". The participants have indicated that for one to lose their lives it is better to resolve the matter within the family and if it fails, then the traditional courts may intervene. This is how one participant responded:

"The reason why we are reluctant to disclose child sexual abuse incidents is because perpetrators who are mostly fathers of our children make threatening statements such as: 'should it be known to anyone, I will kill you. They even threaten children about killing their mothers. So we have a fear of losing our lives should we report such cases to the legal authorities and we even make it clear to our children not to talk about it with anyone. The matter is discussed within the family and if it fails, then we involve the traditional courts. This works for us".

The findings are consistent with the previous studies in that the reluctance of children to disclose sexual abuse stems from fear of the perpetrator (Ferrara, 2002; Kinnear, 2007; Rapholo, 2018; Spies, 2006). Some perpetrators threaten children with statements such as "If you tell anyone, I will kill you/kill your mother."

\subsection{The Spirit of Ubuntu}

Ubuntu is an African principle valuing the interconnectedness and harmony amongst people who live together in one space. Tellinger (2013) and Sekudu (2019) denote that these kind of people hold an understating that they belong to the whole. It was established in this study that most families in the Bapedi tribe practice Ubuntu. Findings revealed the spirit of Ubuntu amongst families in the Bapedi tribe as another factor which contributes to the non-disclosure of child sexual abuse. One participant indicated that together with their children they fear to betray a parent (who is the father of the child in this case), and/or fear the punishment or other negative consequences that the parent may incur as a result of the disclosure of the sexual abuse. Instead, they keep sexual abuse as a secret and something which they can discuss with the perpetrator at home and get rid of it. One participants stated that:

"...but what does humanity say. We cannot let the poor man suffer the consequences of what he might have mistakenly done. It will be sort of betraying him should the matter be disclosed or reported to the legal authorities".

These findings compare very well with what Chabeletsane (2015), Gogela (2013), Kinnear (2007) and Rapholo (2018) have found that because most perpetrators of sexual abuse against children in most communities are family members such as fathers of children, such cases are not easily disclosed because of children and caregivers' fear of betraying the other family member or letting him suffer the consequences of abuse. It can be deduced from these findings that the Bapedi tribe still value the spirit of Ubuntu. This supports what Mathebane (2017) and Sekudu (2019) postulate that in most African families, members of a family try to stick together and protect one another. However, sexual abuse incidents leave children under serious consequences due to the secrecy of sexual abuse amongst family members. This has been confirmed in several studies that child sexual abuse has serious implications on children (Borg et al., 2014; Daray et al., 2016; Rapholo, 2014; Rapholo, 2018; Widom \& Massey, 
2015). The implications of child sexual abuse amongst others include; psychological, physical, social and health effects.

\subsection{Socio-Economic Status of the Family and the Relationship With the Perpetrator}

Several studies have shown that socio-economic status of the family contribute to the non-disclosure of child sexual abuse (Ferguson, 2004; Rapholo, 2014; Chabeletsane, 2015). Most child sexual offences are not disclosed because most women depend solely on men or their partners for an income. Some participants purported that most sexual perpetrators against children are the biological fathers of children who are also breadwinners in their families. This is in line with Goodman-Brown et al. (2003) who established that the majority of the perpetrators are acquaintances or relatives of the victims (children). It was found that most families amongst the Bapedi tribe depend on men for survival within their households and that, should child sexual abuse incidents be disclosed, the family would lose the breadwinner and the family will start to starve. Some participants further indicated that it is not advisable to disclose sexual abuse against children in order to avoid breaking the relationships within the family. The other participant echoed that:

"Sometimes children do not disclose abuse because they are trying to protect the relationship with the perpetrators, more especially in instances where they are their fathers. So as us their caregivers, we don't disclose. We have a fear that such fathers might stop meeting the needs of children, more especially if they are the bread winners. We also fear to lose security from them".

In the same wavelength, the other participant stated that:

"If child sexual abuse is disclosed, such might affect or destroy the connectedness or the relationship within the family, more especially if the perpetrator is the breadwinner.

The socio-economic status of the family amongst the Bapedi tribe has an influence on the non-disclosure of child sexual abuse, especially when the perpetrator is the breadwinner within the family. Findings revealed children's relationship with perpetrators and fear of losing the breadwinner as an influential factor for not disclosing sexual abuse amongst Bapedi tribe. The findings correlate with Madu (2001) and Rapholo (2018) studies in South Africa on sexual abuse and victim-perpetrator relationships who established that the child's relationship to the perpetrator has an impact on the non-disclosure of sexual abuse. It can therefore be deduced from this findings that Bapedi tribe value family relationships and that they mostly depend on fathers of children to provide for the basic needs of the family. Unfortunately this practice leave children vulnerable to sexual abuse in the expense of maintaining good family relationships.

\subsection{Fear of Victimisation}

Most sexual offences are not disclosed because of fear of stigma, labelling and victimisation (Van der Westhuizen, 2011). Some participants indicated that they are reluctant to disclose sexual offences against their children because the child might turn to be a mischievous victim of sexual abuse within the community and nearby communities. Some have a fear that their children might be labelled or be given derogatory names by friends and members of the community, more especially if its boy children who have been sexually abused by adult men. The participants avowed that once the child is labelled as the victim of child sexual abuse, the continuation of the abuse whereby everyone within the community will take advantage of the child is possible. This can be well compared with the findings by Taylor and Norma (2012) and Rapholo (2014) that once the child has been labelled as the victim of sexual abuse, there is the possibility of the continuation of the abuse since everyone within the community will take advantage of that child. One participant echoed that:

"Sometimes our culture makes boys not to disclose sexual abuse if they were involved with people of the same sex because they fear to be labelled as gays, and the same applies to ladies wherein they are more likely to be labelled as lesbians. That might result in the community member taking an advantage of victimizing the child".

In the same wavelength, the other participant indicated that:

"We fear to disclose child sexual abuse more especially if it is of same sex because our culture perceives such as a taboo and the community members will label our children, and they will end up being the victims of sexual abuse forever. It is better to keep quiet".

Findings show that Bapedi tribe believe mostly on the privacy of family matters. This has been emphasised by the participant who indicated that it is better to keep quite if the boy child is alleged to be sexually abused by a male adult. All these were said to be due to fear of being labelled and victimised by the communities. The previous studies also concur with this finding in that it is difficult for boys to disclose sexual abuse by men, because such admission requires confession to having been victimised, which is a blow to their masculine image (Fontes \& 
Plummer, 2010). Literature states that this can be due to the fact that boys that are being sexually abused by men are suspected to be gays and that is where the issue of stigma comes in.

\subsection{Protecting the Dignity of the Family}

In most of the African families, the dignity or status of the family is of paramount importance. Some participants have indicated that a family in their culture is respected. They have indicated that should the information be divulged that their children are victims of sexual abuse, the dignity or status of the family gets compromised in that none within the community will portray any respect to their families. To these point, other participants have stated that the matter then becomes a family issue that can be resolved amongst themselves without the third person and that if the matter fails within the family, then the traditional courts intervene. The following is an assertion made by one of the participants:

"In our culture a family is much to be respected. Should the incident of sexual abuse against children be disclosed to the third parties, the concerned family will lose its status and dignity, so it is better to resolve the matter within the families affected and if it fails, then we can seek counsel from the traditional courts".

Findings revealed the protection of the status and dignity of the family amongst Bapedi tribe as an influential factor for the non-disclosure of child sexual abuse. These findings correlate with the previous studies in that family and social statuses have an impact on the non-disclosure of child sexual abuse (Meadow et al., 2007), thus forcing children and their families to keep sexual abuse secretive. The researcher is of the view that the protection of family dignity and status render children vulnerable to sexual abuse. It is therefore imperative that families be educated about the implications of not disclosing and/or reporting sexual abuse against children.

\subsection{Fear of Witchcraft}

Very few participants indicated that witchcraft in their communities is real and makes them fear to disclose any information about sexual abuse against their children more especially of the alleged perpetrator is someone outside their families or from the traditional healers' family. One participants echoed that:

"Witchcraft exists in our communities. If you want to lose your child, just tell people that so and so has raped your child, more especially if it is someone outside the family or from the traditional healer's family. The best is to keep quiet for the future sake of our children".

Even though not all participants mentioned witchcraft as a factor for not disclosing child sexual abuse, it seems to contribute to the non-disclosure of child sexual abuse amongst Bapedi tribe.

\subsection{Cultural Beliefs}

The notion of children sexual abuse varies from culture to culture (Ngubane, 2010; Chabeletsane, 2015; Rapholo, 2018). Findings of this study revealed cultural beliefs as influential for the non-disclosure of child sexual abuse amongst Bapedi tribe. Most participants indicated that in their culture they only know rape as sexual abuse whilst other forms of sexual abuse as outlined in the South African legislative frameworks are regarded as minor things or taboos, especially if it is an abuse regarding a male adult and a boy. The participants have indicated that these incidents do not need to be taken to the legal authorities for the sake of protecting the status of the family, but instead can be resolved by the families affected. The other participant asserted that:

"Child sexual abuse is a forceful sexual penetration by the male adult with the female child. In our culture when a man have sex with the other man, we perceive that as a taboo and it is unusual. In case such matters arise, the two affected families sit down and resolve the matter among themselves not allowing anyone to know. If it is disclosed the dignity of the family and the image of the child will be affected".

In the same breath, the other participants stated that:

"In most cases, rape is viewed as child sexual abuse in our culture. These other forms of molestations are just being known recently. Our culture regards them as taboos".

Some participants stated that in order to resolve the minor sexual offences the perpetrator's family can compensate the child victim's family with a cow and/or anything agreed upon. They believe that families should not quarrel due to minor things which they can resolve without involving law officials. One of the participants echoed that:

"In our culture some of these things are minor things and taboos. We cannot allow to fight each other due to what we can talk about as the affected families. It would not be nice to see someone's child in prison. Imagine if it was your own child."

Cultural sensitivity in the Bapedi tribe is normal, however, in the context of this paper it leaves children vulnerable to sexual abuse. Findings show that the Bapedi tribe is very sensitive when defining and addressing child sexual 
abuse. It has been discovered that it is not every sexual offence as outlined in the South African pieces of legislation that the Bapedi tribe regards as such, hence their non-disclosure of incidents like that. Findings clearly validates the previous studies that the definition of child sexual abuse vary across cultures (Dawes \& Higson-Smith, 2005; Chabeletsane, 2015; Rapholo, 2018). It can also be seen in this study that Bapedi tribe believes in protecting one another from the law outcomes. This is validated by Sekudu (2019) who states that Africans believe in the sense of interconnectedness at all times, including through painful and joyous situations. However, these leaves children at risk in the name of cultural beliefs. Fontes (2005) states that many children who are physically or sexually abused go unheard, unassisted and unprotected. It is therefore crucial that Bapedi tribe and their traditional courts be educated about what constitutes child sexual abuse and the implications for not reporting it.

\section{Discussion}

This study explored and described the influential factors on the non-disclosure of child sexual abuse amongst Bapedi tribe in Polokwane in the Limpopo province of South Africa. Findings have shown that most sexual offences against children amongst Bapedi are intra-familial and that due to the spirit of Ubuntu, such cases are resolved within the families so as to not allow the other party (perpetrator) to suffer the consequences in a harsh manner, for example, spending the rest of their lives in prison. These findings are in line with the results of previous studies conducted by Goodman-Brown (2003) stating that children are least likely to disclose sexual abuse when the perpetrator is a biological parent. Findings revealed that the perpetrators' families amongst Bapedi tribe do compensate the child victim families by paying a damage through a cow and/or anything agreed upon in a way of preventing it from becoming known and being it reported for legal intervention. Furthermore, it was found that child victims do not disclose sexual abuse because of the fear of threats made by perpetrators, such as, "Should you tell anyone, I will kill you or your mother. As a results sexual abuse against children end up being unreported. Findings have also shown children's relationship with perpetrators as contributing to the non-disclosure of sexual abuse amongst Bapedi tribe. It was indicated that due to the fact that most perpetrators are the biological parents of the children alleged to be sexually abused and that they are the breadwinner within the family, make such cases remain family matters due to the fear of losing the family breadwinner. The dignity and status of a family is highly valued amongst Bapedi which also contributes in the non-disclosure of child sexual abuse. It is believed that should it be known that a child in the family has been sexually abused, the community might start to despise the dignity of the victim child's family and label and/or victimise the concerned child. Fear of witchcraft also came out in this study as one of the possible factors influencing the non-disclosure of child sexual abuse in the context of Bapedi tribe. This validates findings from Rapholo's (2014) study that most Pedi speaking caregivers of children amongst are reluctant to disclose sexual abuse against children because of fear of being bewitched by the perpetrators' families. In addition, it was found that the belief amongst Bapedi tribe is that sex is a taboo, specifically if it is done by people of the same sex. When boy children are being sexually abused by adult males, such incidents amongst Bapedi tribe are taboo and can be resolved by families affected in order to protect the family status and dignity. Hence it is not reported for legal intervention. Paton (2009) supports the findings from this study that child sexual abuse is still a taboo topic for many people across cultures. It was also found that only rape in the context of Bapedi tribe is sexual abuse and other sexual offences are minor things which can be resolved by the affected families with the intervention of traditional courts in case such families fail. The Bapedi tribe believes in the interconnectedness and solidarity in both painful and joyous situations. Findings have revealed that the Bapedi tribe are reluctant to disclose child sexual abuse because of protecting the perpetrator from spending their lives in prison.

In can therefore be noted from the findings of this study that children amongst the Bapedi tribe are more likely to suffer a continuous sexual abuse which is silently being alleged to be dealt with by the affected families due to a variety of contextual factors. However, such practices compromise the well-being of children. Several studies have confirmed that sexual abuse against children has psychological, social, physical and health impacts on the well-being of children. In is therefore imperative that the Bapedi tribe be educated about legal frameworks on child sexual offences and the implications of not disclosing or reporting such.

\section{Conclusion}

The researcher concludes that there is inadequate knowledge of child sexual offences amongst the Bapedi tribe. Children amongst the Bapedi tribe seem to be suffering a lot on sexual abuse, more especially intra-familial abuse. The Bapedi values and beliefs contribute enormously on the non-disclosure of child sexual abuse. Therefore, there is a need for the compilation of more programmes to address the processes of disclosing child sexual abuse amongst the Bapedi tribe. Various stakeholders must work together and be committed to prevent the 
non-disclosure of child sexual abuse. The traditional leaders must also be involved in addressing this integral part of not disclosing child sexual abuse and the implications of not doing so. Lastly, further research on this topic should be conducted in a larger sample in the context of other tribes within the Limpopo province. This will help identify possible contributory factors on the prevalence of child sexual abuse in the province. Policy makers and programme developers can through this background be enlightened on the prevalence of child sexual abuse, not only in the Bapedi tribe but worldwide to enable them formulate or revise policies and programmes aimed at addressing child sexual offences.

\section{Competing Interests Statement}

The authors declare that there are no competing or potential conflicts of interest.

\section{References}

Borg, K., Snowdon, C., \& Hodes, D. (2014). Child sexual abuse: recognition and response when there is a suspicion or allegation. Paediatrics and Child Health, 24(12), 536-543. https://doi.org/10.1016/j.paed.2014.07.012

Botma, Y., Greeff, M., Mulaudzi, F. M., \& Wright, S. (2010). Research in health sciences. Cape Town.Heinemann, Pearson Education South Africa.

Calitz, F. J. W. (2011). Psycho-legal challenges facing the mentally retarded rape victim. South African Journal of Psychology, 17(3), 66-72. https://doi.org/10.4102/sajpsychiatry.v17i3.280

Chabeletsane, S. B. (2015). The perceptions of Setswana parents regarding the disclosure of child sexual abuse (Doctoral dissertation).

Cronch, L. E., Viljoen, J. L., \& Hansen, D. J. (2006). Forensic interviewing in child sexual abuse cases: Current techniques and future directions. Aggression and violent behavior, 11(3), 195-207. https://doi.org/10.1016/j.avb.2005.07.009

Daray, F. M., Rojas, S. M., Bridges, A. J., Badour, C. L., Grendas, L., Rodante, D., ... \& Rebok, F. (2016). The independent effects of child sexual abuse and impulsivity on lifetime suicide attempts among female patients. Child abuse \& neglect, 58, 91-98. https://doi.org/10.1016/j.chiabu.2016.06.011

Dawes, A., \& Higson-Smith, A. K. (2005). Sexual abuse of young children in Southern Africa. Pretoria: Van Schaik.

De Voe, E.R. \& Faller, K. C. (2002). Questioning strategies in interviews with children who may have been sexually abused. Child Welfare League, LXXXI, 5-32.

Esposito, C. (2012). Child sexual abuse and disclosure. New South Wales, Department of Family and Community Services Annual Statistical report 2009-2012.

Ferguson, H. (2004). Protecting children in time: child abuse, child protection and the consequences of modernity. New York, NY: Palgrave Macmillan. https://doi.org/10.1057/9780230006249_1

Ferrara, F. F. (2002). Childhood sexual abuse: development effects across the lifespan. USA: Wadsworth Publishers.

Fontes, L. A. (2005). Child abuse and culture: Working with diverse families. New York: Guilford

Fontes, L. A., \& Plummer, C. (2010). Cultural issues on disclosure of child sexual abuse. Journal of Child Sexual Abuse, 19(5), 491-518. https://doi.org/10.1080/10538712.2010.512520

Fouché, C. B., \& Schurink, W. (2011). Qualitative research designs. In A. S., De Vos, H., Strydom, C. B., Fouché, \& C. S. L., Delport, (Eds.), Research at grass roots: for the social sciences and human services professions (pp. 307-327). Pretoria: Van Schaik.

Getz, L. (2013). Parental/caregiver support of child sexual abuse. Retrieved 7 March, 2013, from http://www.socialworktoday.com

Gogela, S. (2013). Reasons for the reluctance to disclose sexual abuse by middle childhood children (Doctoral dissertation).

Goodman-Brown, T. B., Edelstein, R. S., Goodman, G. S., Jones, D. P. H., \& Gordon, D. S. (2003). Why children tell: a model of children's disclosure of sexual abuse. Child Abuse \& Neglect, 27(5), 525-540. http:/dx.doi.org/10.1016/s145-2134 (03)00037-1

Greeff, M. (2011). Information collection interview. In A. S., De Vos, H., Strydom, C. B., Fouché, \& C. S. L., 
Delport, (Eds.), Research at Grass roots: for the social sciences and human service professions (pp. 341-375). Pretoria: Van Schaik.

Kinnear, K. L. (2007). Childhood sexual abuse: A reference handbook. ABC-CLIO.

Lamb, M. E., Hershkowitz, I., Orbach, Y., \& Esplin, P. W. (2008). Tell me what happened: structured investigative interview of child victims and witnesses. https://doi.org/10.1002/9780470773291

Madu, S. N. (2001). Childhood forcible sexual abuse and victim-perpretrator relationship among a sample of secondary school students in the Northern Province, South Africa. Retrieved 20 Jun., 2013, from http://www.crisa.org.za/downloads/rape.pdf

Malloy, C., \& Lyon, D. (2013). Caregiver support and child sexual abuse: why does it matter? Retrieved 7 March, 2013, from http://www.deafed-child-neglect.col.wiki-edu.m

Mathebane, M. S. (2017). Towards indigenous social work practice guidelines for assisting African families raising children with Down syndrome (Doctoral dissertation).

Mbedzi, P. (2019). Ecosystems. In van Breda \& Sekudu, Theories of Decolonial social work practice in South Africa (1st ed.), South Africa. Oxford University Press.

Meadow, R., Mok, J., \& Rosenberg, D. (2007). ABC of child protection. Australia: Blackwell Publishers.

Ngubane, S. J. (2010). Gender roles in the African culture: implications for the spread of HIV/AIDS. Retrieved 5 Aug. 2013, from https://scholar.sun.ac.za/bitstream/10019.../Ngubane,\%205.J.pdf

Ntlatleng, M. J. (2011). Circumstances that influence the finalisation of child sexual abuse cases in Tembisa. Potchefstroom: NWU (Mini-dissertation-MA Social Work: Forensic Practice).

Rapholo, S. F. (2014). Perceptions of Pedi-speaking caregivers regarding the disclosure of child sexual Abuse (Doctoral dissertation).

Rapholo, S. F. (2018). Effectiveness of interviewing techniques with the black child during forensic social work assessments: South African perspective (Doctoral dissertation).

Rapholo, S. F., \& Makhubele, J. C. (2019). Forensic Interviewing Techniques in Child Sexual Abuse Allegations: Implications for the South African Context. Global Journal of Health Science, 11(6). https://doi.org/10.5539/gjhs.v11n6p53

Rubin, A., \& Babbie, E. R. (2005). Research methods for social work. Australia: Thomson Brooks/Cole.

Sekudu, J. (2019). Ubuntu. In van Breda \& Sekudu, Theories of Decolonial social work practice in South Africa (1st ed.). South Africa: Oxford University Press.

Shackel, R. (2009). Understanding children's medium for disclosing sexual abuse: A tool for overcoming potential misconception in the courtroom. Psychiatry, Psychology and Law, 16(3), 379-393. https://doi.org/10.1080/13218710903040280

South Africa. (2017/2018). South African Police Service. Crime statistics overview RSA 2017/2018.

South Africa. (2005). Children's Act, No 38 of 2005. Pretoria: Government Printers

Spies, G. M. (2006). The effect of sexual abuse on a child. Sexual abuse: Dynamics, assessment and healing (pp. 44-58).

Spies, G. M. (2006). The effect of sexual abuse on a child. In G. M. Spies (ed.), Sexual abuse: dynamics, assessment and healing (pp. 44-61). Pretoria: Van Schaik.

Sumampouw, N. E., Otgaar, H., La Rooy, D., \& de Ruiter, C. (2019). The Quality of Forensic Child Interviewing in Child Sexual Abuse Cases in Indonesia. Journal of Police and Criminal Psychology, 1-12. https://doi.org/10.1007/s11896-019-09342-5

Taylor, S. C., \& Norma, C. (2012). The "symbolic protest" behind women's reporting of sexual assault crime to police. Feminist Criminology, 7(1), 24-47. https://doi.org/10.1177/1557085111420416

Tellinger, M. (2013). Ubuntu Contributionism: A blueprint for human prosperity. Waterval Boven: Zulu Planet Publishers

Van Der Westhuizen, J. E. (2011). A social group work programme with adolescent orphans in foster care affected by HIV and AIDS: North West Province. Potchefstroom: NWU (Thesis - PhD).

Weyer, M. L., \& Geyer, L. S. (2011). The theory and practice of community work: A Southern African perspective. 
Keurkopie.

Wickham, R. E., \& West, J. (2002). Therapeutic work with sexually abused children. Sage.

Widom, C. S., \& Massey, C. (2015). A prospective examination of whether childhood sexual abuse predicts subsequent sexual offending. JAMA pediatrics, 169(1), e143357-e143357. https://doi.org/10.1001/jamapediatrics.2014.3357

\section{Copyrights}

Copyright for this article is retained by the author(s), with first publication rights granted to the journal.

This is an open-access article distributed under the terms and conditions of the Creative Commons Attribution license (http://creativecommons.org/licenses/by/4.0/). 